\title{
Self-assessment of intercultural communication skills: a survey of physicians and medical students in Geneva, Switzerland
}

\author{
Patricia Hudelson ${ }^{1 *}$, Noelle Junod Perron ${ }^{1}$ and Thomas Perneger ${ }^{2}$
}

\begin{abstract}
Background: Physicians working with multicultural populations need to know how to elicit the patient's understanding of the illness; determine the patient's sociocultural context and identify any issues that might affect care; communicate effectively across patient-provider social and cultural differences; and collaborate effectively with an interpreter. Skills self-assessment can contribute to identifying training needs and monitoring skills development in these areas.
\end{abstract}

Methods: As part of a larger study exploring the knowledge, attitudes and practices of Geneva physicians and medical students regarding the care of immigrant patients, we asked respondents to self-rate their ability to perform a range of common yet challenging intercultural communication tasks.

Results: Overall, respondents rated themselves less competent at intercultural tasks than at basic medical skills and less competent at specific intercultural communication skills than at general intercultural skills. Qualified doctors (as opposed to students), those with greater interest in caring for immigrants, and those who rarely encountered difficulties with immigrants rated themselves significantly more competent for all clinical tasks. Having a higher percentage of immigrant patients and previous cultural competence training predicted greater self-rated intercultural communication skills.

Conclusion: Our self-assessment results suggest that students and physicians should be provided with the opportunity to practice intercultural skills with immigrant patients as part of their cultural competence training. To strengthen the validity of self-assessment measures, they should ideally be combined with more objective methods to assess actual skills.

Keywords: cultural competence, self-assessment, intercultural communication, immigrants

\section{Background}

Physicians who work with multiethnic and multilingual patient populations need to know how culture and language can influence clinical communication and care, and learn the skills necessary to identify and respond effectively to patients' diverse needs $[1,2]$. Such skills include the ability to elicit the patient's understanding of the illness; determine the patient's sociocultural context and identify any issues that might affect care;

\footnotetext{
* Correspondence: Patricia.Hudelson@hcuge.ch

'Department of Community Medicine, Primary Care and Emergency Medicine, University Hospitals of Geneva, 4, rue Gabrielle-Perret-Gentil, 1211 Geneva 14, Switzerland
}

Full list of author information is available at the end of the article communicate effectively across patient-provider social and cultural differences; and collaborate effectively with an interpreter [3-5].

In Geneva, Switzerland, cultural and linguistic differences between patients and health care providers are common. Approximately 40\% of the Geneva population are of non-Swiss nationality (195 in total), and half of these speak a language other than French as their native language [6]. At the University Hospitals of Geneva, $50 \%$ of patients and $50 \%$ of staff are of non-Swiss nationality [7], and according to a recent staff survey $28 \%$ of physicians are non-native speakers of French [8]. Despite the historic diversity of the Geneva population [9], the integration of intercultural communication and 
care topics into the medical curriculum is a relatively recent development [10].

In order to gain a general picture of the intercultural challenges faced by Geneva physicians and inform the development of targeted training activities, we conducted a large-scale survey of physicians' and medical students' knowledge, attitudes and skills related to care of immigrant patients. This paper reports on respondents' self-assessments of their clinical and intercultural skills.

\section{Methods}

\section{Study population and data collection}

A self-administered questionnaire was mailed to doctors and medical students in Geneva, Switzerland. A list of all 1400 physicians working in 11 medical departments at the University Hospitals of Geneva was obtained from the Human Resources department, and a list of all 1800 physicians working in private practice was obtained from the Geneva Medical Association. For each list separately, we assigned a random number to each physician, sorted the physicians in numerical order, and took the first 600 physicians on each list. We also included all 250 local medical students in their clinical years (years 4, 5 and 6) in our sample. The questionnaire was mailed again to non-respondents at 4 and 8 weeks after the initial survey.

\section{Study variables}

The questionnaire, which has been described in more detail elsewhere [11] and is available as additional file 1 on the BMC Medical Education website(Hudelsonquestionnaire-migrants.pdf), contained questions about respondents' sociodemographic and professional characteristics; their attitudes, opinions and experiences related to the care of immigrant patients; respondents' self-evaluation of clinical and intercultural skills; and vignettes that probed respondents' ability to identify social and cultural factors affecting health and health care that should be explored with a patient, and knowledge of how to collaborate effectively with an interpreter.

In Geneva, the French term "migrant" (immigrant) is often narrowly associated with asylum seekers. In our study, we explicitly asked respondents to think of immigrants as all persons born and raised outside of Switzerland, in order to encourage them to focus more broadly on patients likely to present cultural and linguistic differences. Most questionnaire items were newly developed or adapted by us. The questionnaire was written in French. The study was approved by the research ethics committee at the University Hospitals of Geneva, and funded by the Swiss Federal Public Health Office.

\section{The self-evaluation questions}

For the self-evaluation of clinical skills, respondents were asked, "To what degree do you consider yourself competent in the following tasks" $(1=$ not at all competent; 5 = perfectly competent). The 14 tasks (see Table 1) included 2 general medical tasks (tasks 1-2), 6 general psychosocial/communication tasks (tasks 2-8), and 6 tasks more specific to immigrant patients (tasks 9-14). Items were developed to reflect common yet challenging clinical and intercultural situations [12-14].

Our main interest was to explore self-assessed competency in intercultural communication and care. However, because skills self-assessments have been associated with a number of problems [15], we attempted to strengthen the validity of results by including general medical tasks (at which we expected most respondents to feel quite competent) and general psychosocial/communication tasks (at which we expected respondents to feel somewhat less competent) in order to situate respondents' self-assessments of intercultural skills within a broader range of clinical tasks.

\section{Statistical analysis}

We obtained distributions of each of the 14 self-evaluation items on the 5-point competency scale. Then we performed an exploratory factor analysis to group items that co-vary together. This analysis yielded 3 subscales. For each subscale, we obtained the internal consistency coefficient (Cronbach alpha) based on the corresponding items, and we computed a summary score as the mean value of the items, rescaled between 0 ("not at all competent" for all items) and 100 ("perfectly competent" for all items). The summary score was considered to be missing if more than half of the scale items were missing. We obtained means and standard deviations for the 3 scores.

We examined the means of the 3 summary scores across respondent subgroups, defined by the respondent's professional status (doctor in private practice, hospital doctor, medical student), sex, age group, nationality (Swiss or other), work experience in a foreign country, percentage of immigrant patients $(0-10 \%, 11$ $30 \%, 31-100 \%)$, interest in caring for immigrant patients (none to very high), difficulties in communicating with immigrant patients (with all cases to almost never), and training in cultural competence (yes/no). We used analysis of variance to test differences between groups. For ordinal predictor variables (such as interest in caring for immigrant patients), we obtained tests of linear trend within the analysis of variance (this test separates the between-group sum of squares into a linear component, using one degree of freedom, and an extra-linear component). Then, we constructed a multivariate regression model for each summary score that included only 
Table 1 Frequency distributions (\%) of items that probe self-assessed competency in 14 clinically relevant tasks

\begin{tabular}{|c|c|c|c|c|c|}
\hline & $\begin{array}{c}\text { Not at all } \\
\text { competent } \\
\square\end{array}$ & & & & $\begin{array}{c}\text { Perfectly } \\
\text { competent } \\
\nabla\end{array}$ \\
\hline 1) Obtain a medical history that is relevant to the patient's complaint & 0.0 & 2.8 & 18.3 & 55.1 & 23.8 \\
\hline 2) Perform a clinical examination that is targeted at the patient's chief complaint & 0.2 & 2.4 & 12.4 & 52.8 & 32.2 \\
\hline 3) Obtain a psychosocial history from the patient & 1.3 & 11.4 & 26.9 & 43.2 & 17.3 \\
\hline 4) Announce bad news (e.g., an unfavorable prognosis) & 2.8 & 12.1 & 26.1 & 40.7 & 18.3 \\
\hline $\begin{array}{l}\text { 5) Make sure that an illiterate patient understands the treatment of his chronic disease (e.g., } \\
\text { hypertension, depression, etc.) }\end{array}$ & 3.1 & 16.0 & 39.9 & 32.4 & 8.5 \\
\hline $\begin{array}{l}\text { 6) Explain the reason for refusing an unjustified treatment or investigation to patient who } \\
\text { requests it }\end{array}$ & 0.5 & 10.5 & 32.2 & 44.1 & 12.7 \\
\hline 7) Discuss advantages and risks of unconventional therapies with a patient who uses them & 4.9 & 18.6 & 32.6 & 34.3 & 9.6 \\
\hline 8) Discuss a patient's religious preferences and constraints regarding his treatment & 7.9 & 25.9 & 33.4 & 26.4 & 6.5 \\
\hline $\begin{array}{l}\text { 9) Communicate the importance of medical treatment to a patient who believes that his } \\
\text { illness is due to supernatural causes }\end{array}$ & 8.9 & 24.3 & 34.7 & 24.5 & 7.6 \\
\hline 10) Explore the migration trajectory and possible traumatic experiences of an asylum seeker & 8.8 & 28.8 & 29.1 & 24.7 & 8.7 \\
\hline 11) Work effectively with a professional interpreter & 2.6 & 10.2 & 28.5 & 39.3 & 19.3 \\
\hline $\begin{array}{l}\text { 12) Orient an undocumented immigrant patient towards appropriate medical and social } \\
\text { services }\end{array}$ & 13.0 & 25.3 & 28.2 & 22.5 & 11.0 \\
\hline 13) Perform a physical examination of a Muslim woman who wears a veil & 16.9 & 21.9 & 22.1 & 24.0 & 15.1 \\
\hline 14) Ask questions and give information to the husband of a patient, if she requests it & 3.4 & 13.3 & 29.6 & 35.3 & 18.4 \\
\hline
\end{tabular}

statistically significant predictors $(\mathrm{p}<0.05)$, using general linear models. The analyses were performed using SPSS version 17 [16].

\section{Results}

\section{Description of respondent sample}

The respondent sample has been described previously [11]. In total 619 out of 1450 respondents returned the survey (response rate 42.7\%). Response rate was lower among private doctors (29.8\%) than among hospital doctors $(52.2 \%)$ or among medical students $(54.2 \%$, p < 0.001 ).

Respondents included 176 (28.4\%) doctors in private practice, 306 (49.4\%) hospital-based doctors and 137 (22.1\%) medical students. There were 338 men and 283 women (45.6\%; sex was missing for 1 person). Fiftyeight (9.6\%) were 24 years old or younger, 354 (58.4\%) were 25 to 44 years old, 179 (29.5\%) were 45 to 64 years old, and $15(2.5 \%)$ were 65 years old or older (age was missing for 16). The majority of respondents (538, 86.6\%) were of Swiss nationality.

Four-hundred sixty-three respondents reported a medical specialty (medical students did not); the most frequent were general internal or general medicine (164, 35.4\%), medical subspecialties $(63,13.6 \%)$, psychiatry $(97,21.0 \%)$, surgery $(36,7.7 \%)$, gynecologyobstetrics $(29,6.3 \%)$, anesthesiology $(27,5.8 \%)$, ophthalmology (13, 2.8\%), dermatology (9,1.9\%), ear, nose and throat $(9,1.9 \%)$, geriatrics $(5,1.1 \%)$, and other $(5,1.1 \%)$.
On average, about $30 \%$ of respondents' patients were immigrants (standard deviation 20\%, quartiles 15\%-30\%40\%). $78.1 \%$ had moderate to high interest in caring for immigrant patients, and $64.6 \%$ encountered difficulties in communicating with immigrant patients almost never or in a minority of cases.

Relatively few respondents reported having received any specific training related to caring for patients from other cultures. Rates ranged from $27.7 \%$ for medical students, to $32.5 \%$ for doctors in private practice.

\section{Self-assessed competency}

Respondents rated their competency at 14 clinical tasks (Table 1). As expected, the highest ratings were obtained for the two general medical skills. Eighty-five percent of respondents considered themselves highly skilled (scores of 4 or 5) at obtaining a medical history and $79.9 \%$ considered themselves highly competent to perform a physical examination. Respondents generally scored lower on the psychosocial/communication skills, and lowest on the intercultural communication and care tasks. The one exception was working with an interpreter: $58.6 \%$ of respondents rated themselves highly competent at this task, ranking it fifth out of the 14 tasks.

The factor analysis produced 3 dimensions, which grouped 6 items reflecting general clinical and communication skills, 4 items related to specific intercultural communication topics, and 4 items related to more general intercultural skills (Table 2). 
Table 2 Loadings from the factor analysis of 14 self-assessment items

\begin{tabular}{|c|c|c|c|}
\hline \multirow[b]{2}{*}{ Self-assessment item } & \multicolumn{3}{|c|}{ Factors } \\
\hline & 1 & 2 & 3 \\
\hline 1) Obtain a medical history that is relevant to the patient's complaint & 0.83 & & \\
\hline 2) Perform a clinical examination that is targeted at the patient's chief complaint & 0.72 & & 0.39 \\
\hline 3) Obtain a psychosocial history from the patient & 0.67 & 0.33 & \\
\hline 4) Announce bad news (e.g., an unfavorable prognosis) & 0.61 & 0.32 & \\
\hline 5) Make sure that an illiterate patient understands the treatment of his chronic disease (e.g., hypertension, depression, etc.) & 0.52 & 0.43 & \\
\hline 6) Explain the reason for refusing an unjustified treatment or investigation to patient who requests it & 0.52 & & \\
\hline 7) Discuss advantages and risks of unconventional therapies with a patient who uses them & & 0.48 & \\
\hline 8) Discuss a patient's religious preferences and constraints regarding his treatment & & 0.73 & \\
\hline 9) Communicate the importance of medical treatment to a patient who believes that his illness is due to supernatural causes & & 0.65 & \\
\hline 10) Explore the migratory trajectory and possible traumatic experiences of an asylum seeker & & 0.68 & \\
\hline 11) Work effectively with a professional interpreter & & & 0.65 \\
\hline 12) Orient an immigrant patient without papers toward appropriate medical and social services & & 0.47 & 0.41 \\
\hline 13) Perform a physical examination of a Muslim woman who wears a veil & & & 0.79 \\
\hline 14) Ask questions and give information to the husband of a patient, if she requests it & & & 0.76 \\
\hline
\end{tabular}

We constructed three corresponding scales: a "general clinical and communication skills" scale, an "intercultural communication skills" scale, and a "general intercultural skills" scale. The internal consistency coefficients of these scales were $0.81,0.66$ and 0.69 .

The means and standard deviations were 67.6 (15.3) for the "general clinical and communication skills" scale, 50.9 (18.6) for the "specific intercultural communication skills" scale, and 56.8 (20.5) for the "general intercultural skills" scale.

All scores were lower among medical students than among doctors, and among younger respondents. In addition, the "general clinical and communication skills" score was higher in respondents who had experience working in another country and among those who rarely encountered difficulties with immigrants (Table 3). In multivariate analysis, qualified doctors (as opposed to students), those with greater interest in caring for immigrants, and those who rarely encountered difficulties with immigrants had significantly elevated scores.

Univariate results were similar for the "intercultural communication skills" score; in addition, a higher percentage of immigrant patients and previous training in cultural competence also predicted higher scores (Table 4). In multivariate analysis, the final model again included qualified doctor status, interest in caring for immigrants, and low frequency of difficulties with immigrants.

The "general intercultural skills" score was higher among women, those with previous work experience abroad, and those with a greater proportion of immigrant patients (Table 5). The multivariate model included all these variables, as well as qualified doctor status.

\section{Discussion}

We evaluated physicians' and medical students' selfassessed skills in intercultural communication and care, and compared these to self-rated ability at other, more generic clinical and communication skills. Our study is limited by a relatively low response rate and the likelihood of higher participation of respondents with greater interest in cross-cultural medicine, and therefore we cannot assume that our descriptive results are fully representative of the local physician population. Nonetheless, our results reflect what we would intuitively expect: overall, respondents rated themselves most competent at general medical skills and least competent at intercultural communication skills. The weakest selfrated skills were those in situations with the greatest social and cultural differences between patient and doctor: undocumented immigrants, asylum seekers, patients with illness and religious beliefs at odds with biomedicine. Somewhat reassuring is the finding that more clinical experience, greater interest in and experience with immigrant patients, and training in cross cultural communication seem to be associated with greater self-confidence with regards to intercultural communication and care. This suggests that cultural competence training programs should emphasize exposure to and practical clinical experience with immigrant patients in order to increase physicians' comfort level with intercultural communication and care $[17,18]$. A number of authors have written about the benefits of on-the-job learning $[19,20]$ but others have emphasized that such practical experience should include role modeling and critical reflection in order to counterbalance the potential negative consequences of the medical curriculum on 
Table 3 Scale of "basic clinical skills"- mean scores across subgroups

\begin{tabular}{|c|c|c|c|c|}
\hline & \multicolumn{2}{|c|}{ Univariate comparisons } & \multicolumn{2}{|c|}{ Mean adjusted for all variables in mode } \\
\hline & Mean (SD) & $P$ value & Mean & \\
\hline Status: & & $<0.001$ & & $<0.001$ \\
\hline Doctors in private practice & $70.6(15.1)$ & & 70.9 & \\
\hline Hospital doctors & $70.7(13.8)$ & & 71.5 & \\
\hline Medical students & $57.1(14.6)$ & & 58.0 & \\
\hline Sex & & 0.043 & & NS \\
\hline Women & $66.2(15.1)$ & & & \\
\hline Men & $68.8(15.4)$ & & & \\
\hline Age group & & $<0.001$ & & NS \\
\hline$\leq 24$ years & $53.4(14.2)$ & (linear trend) & & \\
\hline $25-44$ years & $68.3(14.6)$ & & & \\
\hline $45-64$ years & $70.5(15.0)$ & & & \\
\hline$\geq 65$ years & $74.2(13.0)$ & & & \\
\hline Nationality & & 0.78 & & NS \\
\hline Swiss & $67.5(15.7)$ & & & \\
\hline Other & $68.1(13.0)$ & & & \\
\hline Work experience in foreign country & & 0.001 & & NS \\
\hline Yes & $71.5(14.3)$ & & & \\
\hline No & $65.0(15.3)$ & & & \\
\hline Percentage of immigrant patients & & 0.30 & & NS \\
\hline $0-10 \%$ & $67.7(15.5)$ & (linear trend) & & \\
\hline $11-30 \%$ & $66.8(15.2)$ & & & \\
\hline $31-100 \%$ & $69.1(15.0)$ & & & \\
\hline Interest in caring for immigrant patients & & 0.42 & & 0.025 \\
\hline Absent & $69.4(20.5)$ & (linear trend) & 66.7 & (linear trend) \\
\hline Weak & $68.5(13.6)$ & & 64.6 & \\
\hline Moderate & $66.4(14.8)$ & & 64.8 & \\
\hline High & $67.0(14.8)$ & & 67.0 & \\
\hline Very high & $71.8(16.1)$ & & 70.9 & \\
\hline Difficulties in communicating with immigrant patients & & $<0.001$ & & 0.002 \\
\hline All cases or almost & $74.5(22.0)$ & (linear trend) & 70.9 & (linear trend) \\
\hline Majority of cases & $62.1(17.1)$ & & 62.3 & \\
\hline About half the cases & $65.0(14.4)$ & & 64.6 & \\
\hline Minority of cases & $67.7(15.1)$ & & 66.4 & \\
\hline Almost never & $71.4(14.8)$ & & 69.7 & \\
\hline Training in cultural competence & & 0.046 & & NS \\
\hline Yes & $69.6(14.3)$ & & & \\
\hline No & $66.9(15.6)$ & & & \\
\hline
\end{tabular}

attitudes towards immigrant and other underserved populations [21].

An interesting finding was that the factor analysis did not reflect our initial conceptual grouping of clinical skills. A priori, we differentiated between common medical skills (medical history; physical exam), general psychosocial communication skills relevant for all patients, and intercultural skills specific to caring for immigrant patients, hypothesizing that respondents' self-assessments should reflect the amount of emphasis placed on each of these areas in their formal training.
However, the factor analysis found that the general medical and some of the general communications skills were correlated and that intercultural communication topics were differentiated from other (non-communication specific) intercultural skills. These two visions are not contradictory, and in fact the factor analysis may better reflect the amount of exposure and experience that respondents have with regards to the different topics. The local medical curriculum places increasing emphasis on communication skills training, and topics such as obtaining a psychosocial history, announcing 
Table 4 Scale of "intercultural communication skills": mean scores across subgroups

\begin{tabular}{|c|c|c|c|c|}
\hline & \multicolumn{2}{|c|}{ Univariate comparisons } & \multicolumn{2}{|c|}{ Mean adjusted for all variables in model } \\
\hline & Mean (SD) & $P$ value & Mean & \\
\hline Status: & & $<0.001$ & & $<0.001$ \\
\hline Doctors in private practice & $55.0(20.1)$ & & 50.8 & \\
\hline Hospital doctors & $51.4(18.2)$ & & 48.5 & \\
\hline Medical students & $45.1(16.1)$ & & 40.3 & \\
\hline Sex & & 0.64 & & NS \\
\hline Women & $50.6(19.0)$ & & & \\
\hline Men & $51.3(18.3)$ & & & \\
\hline Age group & & $<0.001$ & & NS \\
\hline$\leq 24$ years & $43.1(15.1)$ & (linear trend) & & \\
\hline $25-44$ years & $50.1(18.3)$ & & & \\
\hline $45-64$ years & $54.8(19.7)$ & & & \\
\hline$\geq 65$ years & $56.0(17.0)$ & & & \\
\hline Nationality & & 0.26 & & NS \\
\hline Swiss & $50.6(18.7)$ & & & \\
\hline Other & $53.1(18.0)$ & & & \\
\hline Work experience in foreign country & & 0.002 & & NS \\
\hline Yes & $53.9(18.6)$ & & & \\
\hline No & $49.1(18.4)$ & & & \\
\hline Percentage of immigrant patients & & 0.036 & & NS \\
\hline $0-10 \%$ & $49.3(19.0)$ & (linear trend) & & \\
\hline $11-30 \%$ & $50.6(18.0)$ & & & \\
\hline $31-100 \%$ & $53.5(19.0)$ & & & \\
\hline Interest in caring for immigrant patients & & $<0.001$ & & 0.025 \\
\hline Absent & $42.0(23.2)$ & (linear trend) & 37.9 & (linear trend) \\
\hline Weak & $47.0(19.7)$ & & 42.6 & \\
\hline Moderate & $48.3(17.7)$ & & 45.5 & \\
\hline High & $53.5(17.5)$ & & 51.6 & \\
\hline Very high & $57.8(20.9)$ & & 55.3 & \\
\hline Difficulties in communicating with immigrant patients & & $<0.001$ & & 0.017 \\
\hline All cases or almost & $41.4(21.4)$ & (linear trend) & 40.0 & (linear trend) \\
\hline Majority of cases & $46.0(17.4)$ & & 44.7 & \\
\hline About half the cases & $49.8(17.7)$ & & 48.0 & \\
\hline Minority of cases & $50.0(18.5)$ & & 47.1 & \\
\hline Almost never & $56.3(18.8)$ & & 53.0 & \\
\hline Training in cultural competence & & 0.003 & & NS \\
\hline Yes & $54.3(18.1)$ & & & \\
\hline No & $49.5(18.6)$ & & & \\
\hline
\end{tabular}

bad news and adapting the physician's discourse to patients' comprehension levels are regularly addressed. However, topics such as nonconventional therapies, religious practices and requirements, and cultural beliefs about illness are addressed only sporadically. Topics such as social/medical services for undocumented immigrants, working with an interpreter, conducting a physical exam of a Muslim woman wearing a veil, or adapting to patient's information wishes were addressed until recently only in optional continuing education seminars.
Although our study has provided us with useful information for developing future training activities aimed at strengthening physicians' cultural competence, such selfassessment data should be interpreted with caution. Several studies suggest that higher levels of confidence in intercultural situations may actually reflect lower insight and awareness [22-24]. A study in the US found that medical students actually rated their own cultural competency signficantly higher than that of residents and attending physicians, despite there being no formal training in this area [25]. In our study, the fact that respondents' comparative 
Table 5 Scale of "general intercultural skills": mean scores across subgroups

\begin{tabular}{|c|c|c|c|c|}
\hline & \multicolumn{2}{|c|}{ Univariate comparisons } & \multicolumn{2}{|c|}{ Mean adjusted for all variables in model } \\
\hline & Mean (SD) & $P$ value & Mean & \\
\hline Status: & & $<0.001$ & & $<0.001$ \\
\hline Doctors in private practice & $61.3(20.2)$ & & 61.5 & \\
\hline Hospital doctors & $59.9(18.8)$ & & 60.6 & \\
\hline Medical students & $44.2(19.3)$ & & 46.4 & \\
\hline Sex & & 0.012 & & $<0.001$ \\
\hline Women & $59.0(20.6)$ & & 59.0 & \\
\hline Men & $54.9(20.2)$ & & 53.4 & \\
\hline Age group & & $<0.001$ & & NS \\
\hline$\leq 24$ years & $42.7(19.0)$ & (linear trend) & & \\
\hline $25-44$ years & $56.5(19.9)$ & & & \\
\hline $45-64$ years & $60.8(19.6)$ & & & \\
\hline$\geq 65$ years & $66.4(21.6)$ & & & \\
\hline Nationality & & 0.082 & & NS \\
\hline Swiss & $56.2(20.3)$ & & & \\
\hline Other & $60.4(21.2)$ & & & \\
\hline Work experience in foreign country & & $<0.001$ & & $<0.001$ \\
\hline Yes & $62.4(19.2)$ & & 59.4 & \\
\hline No & $52.7(20.0)$ & & 53.0 & \\
\hline Percentage of immigrant patients & & 0.007 & & 0.016 \\
\hline $0-10 \%$ & 53.9 (18.6) & (linear trend) & 54.1 & (linear trend) \\
\hline $11-30 \%$ & $56.7(20.7)$ & & 55.5 & \\
\hline $31-100 \%$ & $59.9(20.7)$ & & 59.0 & \\
\hline Interest in caring for immigrant patients & & 0.14 & & NS \\
\hline Absent & $58.9(23.5)$ & (linear trend) & & \\
\hline Weak & $53.7(20.6)$ & & & \\
\hline Moderate & $55.4(19.0)$ & & & \\
\hline High & $58.1(20.0)$ & & & \\
\hline Very high & $59.6(24.4)$ & & & \\
\hline Difficulties in communicating with immigrant patients & & 0.14 & & NS \\
\hline All cases or almost & $57.0(26.4)$ & (linear trend) & & \\
\hline Majority of cases & $53.9(21.7)$ & & & \\
\hline About half the cases & $55.4(20.4)$ & & & \\
\hline Minority of cases & $57.7(19.5)$ & & & \\
\hline Almost never & $58.3(20.9)$ & & & \\
\hline Training in cultural competence & & 0.20 & & NS \\
\hline Yes & $58.3(19.0)$ & & & \\
\hline No & $55.9(21.2)$ & & & \\
\hline
\end{tabular}

self-assessments reflected what we would intuitively expect, based on their training and experience, provides us with some degree of confidence that our measures are a true reflection of their comfort levels with intercultural communication and care. Nonetheless, while self-assessment can be a useful method for determining self-confidence in intercultural situations [26-29], actual skills are better assessed using external objective measures such as OSCEs, standardized patients, and simulation [30]. Unfortunately, while many of these methods have been used successfully to evaluate intercultural communication skills in small- scale studies and training contexts [31-35], they are too costly and impractical for larger-scale assessments such as described in this paper. Skills self-assessment is likely to continue to be a widely-used method for identifying training needs [36], and future efforts should focus on developing more objective measures of cultural competency that can be integrated into survey instruments [37].

\section{Conclusion}

Our self-assessment results suggest that students and physicians should be provided with the opportunity to 
practice intercultural skills with immigrant patients as part of their cultural competence training. To strengthen the validity of self-assessment measures, they should ideally be combined with more objective methods to assess actual skills.

\section{Additional material}

Additional file 1: "Questionnaire sur la prise en charge des patients migrants". Questionnaire, in French, exploring the knowledge, attitudes and practices of physicians and medical students regarding the care of immigrant patients.

\section{Acknowledgements}

The study was funded by the Swiss Federal Public Health Office, contract 04.000929.

\section{Author details}

${ }^{1}$ Department of Community Medicine, Primary Care and Emergency Medicine, University Hospitals of Geneva, 4, rue Gabrielle-Perret-Gentil, 1211 Geneva 14, Switzerland. 'Division of Clinical Epidemiology, University Hospitals of Geneva, 4, rue Gabrielle-Perret-Gentil, 1211 Geneva 14, Switzerland.

\section{Authors' contributions}

PH, NJP and TP participated in the design of the study. TP performed the statistical analyses. PH drafted the manuscript. All authors read and approved the final manuscript.

\section{Competing interests}

The authors declare that they have no competing interests.

Received: 23 May 2011 Accepted: 1 September 2011

Published: 1 September 2011

\section{References}

1. Lingard L, Tallett S, Rosenfield J: Culture and physician-patient communication: a qualitative exploration of residents' experiences and attitudes. Ann R Coll Physicians Surg Can 2002, 35(6):331-335.

2. Betancourt JR, Green AR, Carrillo JE: The challenges of cross-cultural healthcare-diversity, ethics, and the medical encounter. Bioethics Forum 2000, 16(3):27-32.

3. Betancourt JR, Green AR, Carrillo JE, Ananeh-Firempong O: Defining cultural competence: a practical framework for addressing racial/ethnic disparities in health and health care. Public Health Rep 2003, 118(4):293-302.

4. Tervalon M: Components of culture in health for medical students' education. Acad Med 2003, 78(6):570-576.

5. Pacheco G: Teaching cultural competence in health care: a review of current concepts, policies and practices. American Institutes for Research (AIR); 2002.

6. Office Cantonale des Statistiques: Études et documents $n^{\circ} 37$ : Portrait statistique des étrangers vivant à Genève. Geneva; 2005.

7. Hôpitaux Universitaires de Genève: Rapport annuel 2009. Geneva, Switzerland; 2009.

8. Hudelson P: Report of the survey "care of immigrant patients at the University Hospitals of Geneva". Geneva: University Hospitals of Geneva; 2011.

9. Bureau de l'intégration: Les Cahiers du BIE no 2: Comment l'immigration évolue et modifie Genève. Genève, Switzerland; 2003.

10. Hudelson P, Stalder H: [Sociocultural diversity and medical education]. Rev Med Suisse 2005, 1(34):2214-2217.

11. Hudelson P, Perron NJ, Perneger TV: Measuring physicians' and medical students' attitudes toward caring for immigrant patients. Eval Health Prof 2010, 33(4):452-472.
12. Hudelson P: Contextualizing cultural competence training of residents: results of a formative research study in Geneva, Switzerland. Med Teach 2006, 28(5):465-471.

13. Hudelson P: Improving patient-provider communication: insights from interpreters. Fam Pract 2005, 22(3):311-316.

14. Priebe S, Sandhu S, Dias S, Gaddini A, Greacen T, loannidis E, Kluge U, Krasnik A, Lamkaddem M, Lorant V, et al: Good practice in health care for migrants: views and experiences of care professionals in 16 European countries. BMC Public Health 11(1):187.

15. Hodges B, Regehr G, Martin D: Difficulties in recognizing one's own incompetence: novice physicians who are unskilled and unaware of it. Acad Med 2001, 76(10 Suppl):S87-89.

16. IBM: SPSS Statistics. Chicago, IL; 172010.

17. Bell $K$, Boshuizen $H$, Scherpbier A, Dornan $T$ : When only the real thing will do: junior medical students' learning from real patients. Med Educ 2009, 43(11):1036-1043.

18. Griswold K, Zayas L, Kernan J, Wagner C: Cultural awareness through medical student and refugee patient encounters. J Immigr Minor Health 2007, 9(1):55-60

19. Wear D, Kuczewski MG: Perspective: medical students' perceptions of the poor: what impact can medical education have? Acad Med 2008, 83(7):639-645.

20. Lie D, Shapiro J, Cohn F, Najm W: Reflective practice enriches clerkship students' cross-cultural experiences. J Gen Intern Med 25(Suppl 2): S119-125.

21. Crandall SJ, Reboussin BA, Michielutte R, Anthony JE, Naughton MJ: Medical students' attitudes toward underserved patients: a longitudinal comparison of problem-based and traditional medical curricula. Adv Health Sci Educ Theory Pract 2007, 12(1):71-86.

22. Kumas-Tan Z, Beagan B, Loppie C, MacLeod A, Frank B: Measures of cultural competence: examining hidden assumptions. Acad Med 2007 82(6):548-557.

23. Nokes KM, Nickitas DM, Keida R, Neville S: Does service-learning increase cultural competency, critical thinking, and civic engagement? J Nurs Educ 2005, 44(2):65-70.

24. Smith-Campbell B: A health professional students' cultural competence and attitudes toward the poor: the influence of a clinical practicum supported by the National Health Service Corps. J Allied Health 2005, 34(1):56-62.

25. Thompson B, Crandall S, Haidet P: Student perceptions of residents, attendings, and their own cultural competency: How do they compare? Nashville, TN: AAMC Southern Group on Educational Affairs; 2008.

26. Shapiro J, Hollingshead J, Morrison E: Self-perceived attitudes and skills of cultural competence: a comparison of family medicine and internal medicine residents. Med Teach 2003, 25(3):327-329.

27. Park ER, Chun MB, Betancourt JR, Green AR, Weissman JS: Measuring residents' perceived preparedness and skillfulness to deliver crosscultural care. J Gen Intern Med 2009, 24(9):1053-1056.

28. Jeffreys MR, Dogan E: Factor analysis of the transcultural self-efficacy tool (TSET). J Nurs Meas 18(2):120-139.

29. Gozu A, Beach MC, Price EG, Gary TL, Robinson K, Palacio A, Smarth C, Jenckes M, Feuerstein C, Bass EB, et al: Self-administered instruments to measure cultural competence of health professionals: a systematic review. Teach Learn Med 2007, 19(2):180-190.

30. Davis DA, Mazmanian PE, Fordis M, Van Harrison R, Thorpe KE, Perrier L: Accuracy of physician self-assessment compared with observed measures of competence: a systematic review. JAMA 2006, 296(9):1094-1102.

31. Robins LS, White CB, Alexander GL, Gruppen LD, Grum CM: Assessing medical students' awareness of and sensitivity to diverse health beliefs using a standardized patient station. Acad Med 2001, 76(1):76-80.

32. Green AR, Miller E, Krupat E, White A, Taylor WC, Hirsh DA, Wilson RP, Betancourt JR: Designing and implementing a cultural competence OSCE: lessons learned from interviews with medical students. Ethn Dis 2007, 17(2):344-350.

33. Perron NJ, Perneger T, Kolly V, Dao MD, Sommer J, Hudelson P: Use of a computer-based simulated consultation tool to assess whether doctors explore sociocultural factors during patient evaluation. J Eval Clin Pract 2009, 15(6):1190-1195.

34. Rosen J, Spatz ES, Gaaserud AM, Abramovitch H, Weinreb B, Wenger NS Margolis CZ: A new approach to developing cross-cultural communication skills. Med Teach 2004, 26(2):126-132. 
35. Kalet AL, Mukherjee D, Felix K, Steinberg SE, Nachbar M, Lee A, Changrani J, Gany F: Can a web-based curriculum improve students' knowledge of, and attitudes about, the interpreted medical interview? I Gen Intern Med 2005, 20(10):929-934.

36. Silver I, Campbell C, Marlow B, Sargeant J: Self-assessment and continuing professional development: the Canadian perspective. J Contin Educ Health Prof 2008, 28(1):25-31.

37. Ho MJ, Lee KL, Green AR: Can cultural competency self-assessment predict OSCE performance? Med Educ 2008, 42(5):525.

\section{Pre-publication history}

The pre-publication history for this paper can be accessed here: http://www.biomedcentral.com/1472-6920/11/63/prepub

doi:10.1186/1472-6920-11-63

Cite this article as: Hudelson et al: Self-assessment of intercultural communication skills: a survey of physicians and medical students in Geneva, Switzerland. BMC Medical Education 2011 11:63.

\section{Submit your next manuscript to BioMed Central} and take full advantage of:

- Convenient online submission

- Thorough peer review

- No space constraints or color figure charges

- Immediate publication on acceptance

- Inclusion in PubMed, CAS, Scopus and Google Scholar

- Research which is freely available for redistribution

Submit your manuscript at www.biomedcentral.com/submit 